\title{
Suppression of HSP27 increases the anti-tumor effects of quercetin in human leukemia U937 cells
}

\author{
XI CHEN, XIU-SHUAI DONG, HAI-YAN GAO, YONG-FANG JIANG, YING-LAN JIN, \\ YU-YING CHANG, LI-YAN CHEN and JING-HUA WANG \\ Department of Hematology, The Second Affiliated Hospital, Harbin Medical University, \\ Harbin, Heilongjiang 150086, P.R. China
}

Received January 12, 2015; Accepted October 21, 2015

DOI: $10.3892 / \mathrm{mmr} .2015 .4600$

\begin{abstract}
Quercetin, a natural flavonoid, inhibits the growth of leukemia cells and induces apoptosis. Heat shock protein 27 (HSP27) has been reported to promote the development of leukemia by protecting tumor cells from apoptosis through various mechanisms. The present study investigated the effects of small hairpin (sh)RNA-mediated HSP27 knockdown on the anti-cancer effects of quercetin in U937 human leukemia cells. Cells were transfected with recombinant lentiviral vector pCMV-G-NR-U6-shHSP27 (shHSP27), which expressed shRNA specifically targeting the HSP27 gene, alone or in combination with quercetin. The results showed that shHSP27 and quercetin synergistically inhibited U937 cell proliferation and induced apoptosis by decreasing the Bcl2-to-Bax ratio. Furthermore, this combined treatment significantly suppressed the infiltration of tumor cells and the expression of angiogenesis-associated proteins HIF1 $\alpha$ and VEGF. Compared with shHSP 27 or quercetin alone, shHSP 27 plus quercetin markedly decreased the protein expression of cyclinD1 and thus blocked the cell cycle at G1 phase. The Notch/AKT/mTOR signaling pathway is important in tumor aggressiveness; quercetin plus shHSP27 significantly decreased Notch 1 expression and the phosphorylation levels of the downstream signaling proteins AKT and mTOR. The inhibitory effects of quercetin plus shHSP27 on this pathway may thus have been responsible for the cell cycle arrest, inhibition of proliferations and infiltration as well as enhancement of apoptosis. Therefore, these findings collectively suggested that suppression of HSP27 expression amplified the anti-cancer effects of quercetin in U937 human leukemia cells, and that quercetin in combination
\end{abstract}

Correspondence to: Ms. Jing-Hua Wang, Department of Hematology, The Second Affiliated Hospital, Harbin Medical University, 246 Xuefu Road, Harbin, Heilongjiang 150086, P.R. China

E-mail: jinghuawang123@163.com

Key words: quercetin, heat shock protein 27, AKT/mammalian target of rapamycin, leukemia with shHSP27 represents a promising therapeutic strategy for human leukemia.

\section{Introduction}

Medicinal herbs are a tremendous source of natural products with anti-cancer activity. Administration of natural products has become an integral part in the prevention and treatment of cancer. These phytochemicals provide potential novel leads for the development of anti-angiogenic drugs $(1,2)$.

Quercetin (3,3',4',5,7-pentahydroxy-flavone) is a polyphenolic substance, which has been shown to have beneficial biological properties due to its anti-oxidative activity as well as the capacity to modify eicosanoid biosynthesis, prevent atherosclerotic plaque formation and platelet aggregation, and to have relaxant effects on cardiovascular smooth muscles (3-5). Of note, quercetin has been demonstrated to induce apoptosis in a variety of tumor cell types, while preventing the apoptosis of certain non-tumorous cell types $(6,7)$. Furthermore, quercetin inhibits angiogenesis of tumors as well as the expression of enzymes that activate carcinogens $(2,8)$. In particular, quercetin has been indicated to inhibit the growth and to induce apoptosis of human leukemia cells by inhibiting the Wnt protein $\beta$-catenin $(9,10)$. Leukemia is among the most common types of cancer worldwide; furthermore, its prevalence has been increasing due to the extended human life, radiation $(11,12)$ and pollution $(13,14)$, as a result of the decrease in the incidence of infectious diseases in developed countries. The incidence of leukemia is higher in developed countries than in developing countries (15). In developing countries, the use of natural plant extracts as remedies against leukemia is common $(15,16)$.

Heat shock proteins (HSPs) are a class of functionally associated proteins with regulatory roles comprising protein synthesis and degradation, prevention of stress-associated injury, apoptosis and the generation of immune responses $(17,18)$. Five types of HSP have been identified in mammalian cells, among which HSP27 has the important biological function of protecting cells from damage arising from various stress factors with phosphorylated HSP27 being considered as a potential diagnostic marker for cancer (19). In leukemia cells, HSP27 is closely associated with proliferation, differentiation and heat resistance (20). Overexpression of 
HSP27 increases the tumorigenicity and protects malignant cells against apoptotic cell death through several mechanisms (21-24).

Previous studies have reported that quercetin downregulates the mRNA and protein expression of HSP27 and increases the sensitivity of tumors to hyperthermia (25-27); however, to the best of our knowledge, the anti-cancer effects of quercetin together with HSP27 interference have not been studied in leukemia cells. The present study aimed to investigate the effects of small hairpin (sh)RNA with specificity against HSP27 (shHSP27) on the anti-tumor effects of quercetin, including the inhibition of cell proliferation and adhesion, induction of apoptosis and cell cycle arrest, in U937 human leukemia cells.

The mammalian target of rapamycin (mTOR) is a central regulator of cell growth, proliferation, differentiation and survival. Studies have shown that mTOR is frequently hyperactivated in cancer and is a crucial regulator of cancer cell motility, invasion and metastasis $(28,29)$. Quercetin has been found to inhibit mTOR signaling during cancer treatment and prevention $(30,31)$. Therefore, the present study also evaluated the regulatory activity of quercetin plus shHSP27 on mTOR signaling in human leukemia U937 cells.

\section{Materials and methods}

Cell culture and reagents. The U937 human leukemia cell line was purchased from the American Type Culture Collection (Manassas, VA, USA) and cultured in RPMI-1640 medium (Hyclone Corp., Logan, UT, USA), supplemented with $10 \%$ fetal bovine serum (Gibco; Thermo Fisher Scientific, Inc., Waltham, MA, USA). Quercetin was purchased from Sigma-Aldrich (St. Louis, MO, USA) and dissolved in dimethyl sulfoxide to a concentration of $50 \mu \mathrm{M}$ and stored at $-20^{\circ} \mathrm{C}$ for use. A Cell Counting Kit 8 (CCK-8) was obtained from JRDUN Biotechnology Co. Ltd (Shanghai, China). An Annexin V-fluorescein isothiocyanate (FITC) apoptosis detection kit and Matrigel were purchased from BD Biosciences (Franklin Lakes, NJ, USA).

Lentiviral vector construction. For knockdown of HSP27 expression, the pCMV-G-NR-U6-shRNA vector (Genechem, Shanghai, China) was used. Three sequences of the human HSP27 gene HSPB1 (GenBank accession no. NM001540) were selected as targets for RNA interference: shHSP27-1 (start, 585 bp); 5'-GCTGCAAAATCCGATGAGA-3'; shHSP27-2 (start, 293 bp), 5'-CCTGGATGTCAACCACTTC-3'; and shHSP27-3 (start, 322 bp), 5'-AGCTGACGGTCAAGA CCAA-3'. In all subsequent experiments, shHSP27-3 was used if not indicated otherwise.

For construction of the lentiviruses, 293T cells (Enzyme-Linked Biological Technology Co., Ltd., Shanghai, China) were transfected using Lipofectamine 2000 (Invitrogen; Thermo Fisher Scientific) with plasmids expressing retroviral proteins Gag-Pol and VSV-G (Addgene, Cambridge, MA, USA). At $48 \mathrm{~h}$ after transfection, supernatants containing the retrovirus were collected and frozen at $-70^{\circ} \mathrm{C}$ until use.

RNA quantification by reverse-transcription quantitative polymerase chain reaction (RT-qPCR). The expression of
HSP27 in U937 cells was quantified by real-time PCR. Total RNA was extracted using the TRIzol reagent (Invitrogen) and $1 \mu \mathrm{g}$ total RNA was reverse-transcribed into cDNA using M-MLV reverse transcriptase in the presence of oligo (dT)12-18. RT-PCR was performed in triplicate with SYBR Green master mix (Toyobo, Osaka, Japan) for $10 \mathrm{~min}$ at $95^{\circ} \mathrm{C}$ for initial denaturation, followed by 40 cycles of $95^{\circ} \mathrm{C}$ for $15 \mathrm{sec}, 58^{\circ} \mathrm{C}$ for $30 \mathrm{sec}$ and $72^{\circ} \mathrm{C}$ for $30 \mathrm{sec}$ in the StepOne ${ }^{\mathrm{TM}}$ Real-Time PCR System (Genuine Biosystem, Chennai, India). The following primers (Generay Biotech Co., Ltd., Shanghai, China) were used: HSP27 forward, 5'-CCAGAGCAGAGT CAGCCAGCAT-3' and reverse, 5'-CGAAGGTGACTGGG ATGGTGA-3'; GAPDH forward, 5'-ACCACAGTCCATGCC ATCAC-3' and reverse, 5'-TCCACCACCCTGTTGCTGTA-3'. GAPDH was used as a reference gene.

Cell proliferation assay. U937 cells were seeded in triplicate into 96-well plates at a density of $2 \times 10^{4}$ cells/well. Cells were treated with medium (control group), empty vector $(50 \mu \mathrm{M} / 1)$, shHSP27 vector $(50 \mu \mathrm{M} / \mathrm{l})$, quercetin $(50 \mu \mathrm{M} / \mathrm{l})$, empty vector plus quercetin or shHSP27 vector plus quercetin. Following incubation at $37^{\circ} \mathrm{C}$ for 0,24 or $48 \mathrm{~h}, 10 \mu \mathrm{l} \mathrm{CCK}-8$ solution was added to each well and subsequent to further incubation for $3 \mathrm{~h}$, the absorbance was detected at a wavelength of $450 \mathrm{~nm}$. The cell proliferation rate (relative to control) of the five treated groups was calculated as follows: Proliferation rate (relative to control $)=($ absorbance of experimental group/absorbance of control group) $\mathrm{x} 100 \%$. All experiments were performed in triplicate.

Flow cytometry. U937 cells at $2 \times 10^{6}$ per well were seeded into a six-well plate and treated with medium, empty vector, shHSP27 vector, quercetin, empty vector + quercetin or shHSP27 vector + quercetin and then cultured for $48 \mathrm{~h}$. Cells were then collected, washed twice with phosphate-buffered saline (PBS) and prepared for analysis of apoptosis and the cell cycle. For the apoptosis assay, cell suspensions were adjusted to a density of 1x10 $/ \mathrm{ml}$ with binding buffer (Thermo Fisher Scientific, Inc.). Annexin V-FITC and propidium iodide (PI) were added to the cell suspension according to the manufacturer's instructions and apoptosis was detected using a BD C6 flow cytometer (BD Biosciences). For cell cycle analysis, the cells were fixed in $2 \mathrm{ml}$ pre-cooled $70 \%$ ethanol at $4^{\circ} \mathrm{C}$ overnight. The cells were washed twice, stained with $400 \mu \mathrm{l}$ PI $(50 \mu \mathrm{g} / \mathrm{ml})$ and $50 \mu \mathrm{g} / \mathrm{ml}$ RNase, and then subjected to flow cytometric analysis.

Cell adhesion assay. An adhesive artificial basement membrane was prepared by adding a mixture of serum-free RPMI-1640 medium and Matrigel at a density of $100 \mu \mathrm{g} / 2,500 \mu \mathrm{l}$ into a 12 -well plate at $250 \mu \mathrm{l} /$ well and drying overnight. U937 cells were seeded into the 12 -well plate at a density of $2 \times 10^{4}$ cells/well and treated with the respective vectors and/or quercetin as described above. Following $48 \mathrm{~h}$ of incubation at $37^{\circ} \mathrm{C}$, the culture medium was discarded and non-adherent cells were removed by rinsing with PBS. Adherent cells were then fixed with methanol for $15 \mathrm{~min}$ at $37^{\circ} \mathrm{C}$ and then stained with crystal violet (JRDUN Biotechnology Co., Ltd., Shanghai, China) for $20 \mathrm{~min}$. The numbers of adherent cells were counted under a microscope (BX51; Olympus, Tokyo, Japan). 

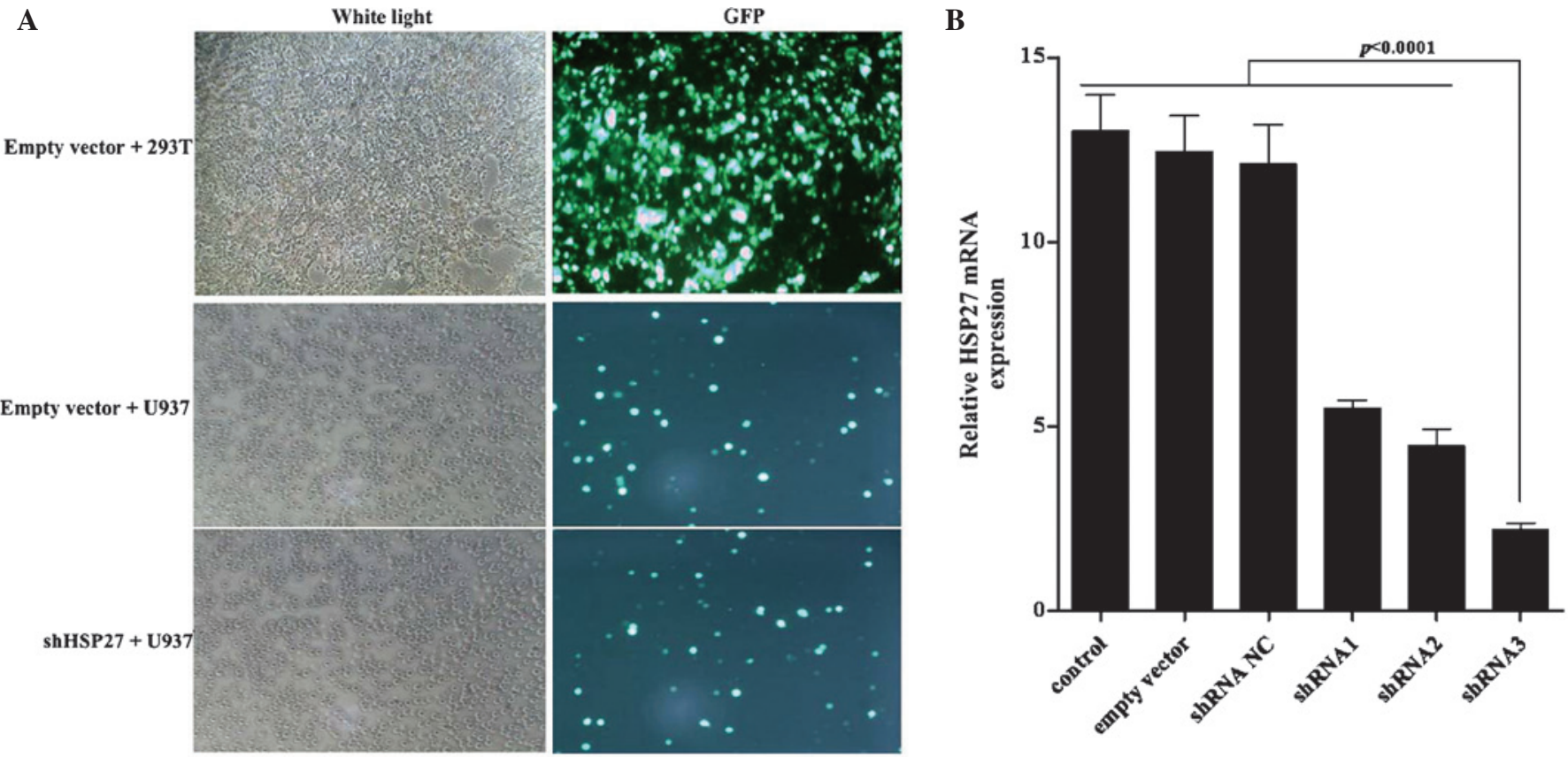

Figure 1. Assessment of HSP27 knockdown in U937 cells. (A) GFP was detected in cells to assess the transfection efficiency (magnification, x100). (B) Relative mRNA expression of HSP27 was analyzed. Values are expressed as the mean \pm standard deviation. P $<0.0001$ vs. the control group. shRNA, small hairpin RNA; NC, negative control; HSP, heat shock protein; GFP, green fluorescent protein.

Western blot analysis. Cells were lysed using radioimmunoprecipitation assay lysis buffer (Keygentec, Nanjing, China) to extract total proteins. The protein concentration was determined using a bicinchoninic acid assay (Keygentec). Protein samples $(30 \mu \mathrm{g})$ were separated by $10 \%$ SDS-PAGE and transferred onto polyvinylidene fluoride membranes (Millipore, Billerica, MA, USA). Membranes were blocked with $5 \%$ non-fat milk at room temperature for $1 \mathrm{~h}$ and incubated overnight at $4{ }^{\circ} \mathrm{C}$ with the following antibodies: B-cell lymphoma 2 (Bcl-2; cat. no. sc-492; 1:100) and Bcl-2associated X protein (Bax; cat. no. sc492; 1:150), from Santa Cruz Biotechnology, Inc. (Santa Cruz, CA, USA); cyclin B1 (cat. no. 12231; 1:1,000), cyclin D1 (cat. no. 2978; 1:1,000), AKT (cat. no. 9272S; 1:1,000), phosphorylated (p)-AKT (cat. no. 4058S; 1:1,000), mammalian target of rapamycin (mTOR; cat. no. 2983; 1:1,000), p-mTOR (cat. no. 5536; 1:800) and hypoxia-inducible factor (HIF) $1 \alpha$ (cat. no. 3176; 1:1,000) from Cell Signaling Technology, Inc. (Danvers, MA, USA); vascular endothelial growth factor (VEGF; cat. no. ab46154; 1:1,000) and Notch1 (cat. no. ab52627; 1:1,000), from Abcam (Cambridge, UK); and GAPDH (cat. no. 5471; 1:1,500; Cell Signaling Technology, Inc.). Membranes were washed three times with Tris- $\mathrm{HCl}(\mathrm{pH} 7.6$; $20 \mathrm{mM}$ ) containing $137 \mathrm{mM} \mathrm{NaCl}$ and $0.01 \%$ Tween-20 and then incubated with horseradish peroxidase-conjugated goat anti-rabbit/mouse secondary antibody (cat. no. A0208/A0216; 1:1,000; Beyotime Institute of Biotechnology, Inc., Shanghai, China) at $25^{\circ} \mathrm{C}$ for $2 \mathrm{~h}$. Membranes were visualized using enhanced chemiluminescence solution (Millipore) and x-ray film. Protein levels were determined by densitometric analysis with normalization to GAPDH.

Statistical analysis. Values are expressed as the mean \pm standard deviation. All statistical analyses were performed using
GraphPad Prism 5.00 software (GraphPad Software, La Jolla, CA, USA). Differences among groups were tested by one-way analysis of variance followed by the Neuman-Keuls post-hoc test. A two-sided P-value $<0.05$ was considered to indicate a statistically significant difference.

\section{Results}

shHSP27 decreases HSP27 expression in U937 cells. Numerous types of cancer cell constitutively express HSP27 at elevated levels, which is associated with drug resistance (32). To inhibit HSP27 expression in U937 human leukemia cells, three pairs of shRNA were designed to specifically target HSP27 and then ligated into the pCMV-G-NR-U6-shRNA vector, which contains a green fluorescent protein (GFP) expression gene for identification. Lentiviruses for the expression of shHSP27 were harvested from the supernatant of 293T packaging cells. U937 cells were transfected with this supernatant containing shHSP27 lentivirus and mRNA expression of HSP27 was detected following $48 \mathrm{~h}$ of incubation. As shown in Fig. 1A, a proportion of the U937 cells were successfully transfected with shHSP27-3 lentivirus and HSP27 mRNA expression was considerably decreased by shHSP27-3 (Fig. 1B).

shHSP27 and quercetin jointly inhibit U937-cell proliferation. Quercetin has been reported to inhibit the proliferation of human leukemia cell lines, including U937 (33,34). At a concentration of $2 \mu \mathrm{M}$, quercetin inhibited the proliferation of U937 cells by $15 \%$ following $24 \mathrm{~h}$ of incubation, which was consistent the findings of a previous study (34). When cells were simultaneously treated with shHSP27, cell proliferation further decreased by $\sim 10 \%$ (Fig. 2A).

mTOR signaling has been reported to stimulate cellular proliferation and aggressive tumor growth in numerous 
A

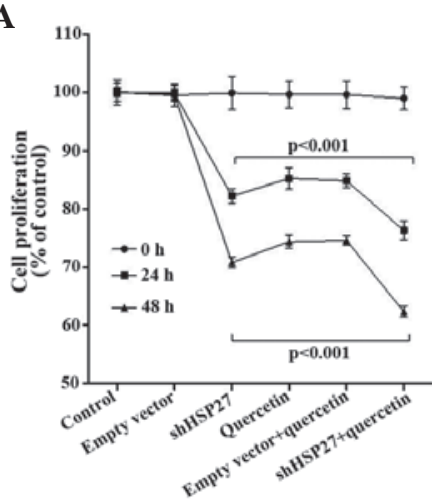

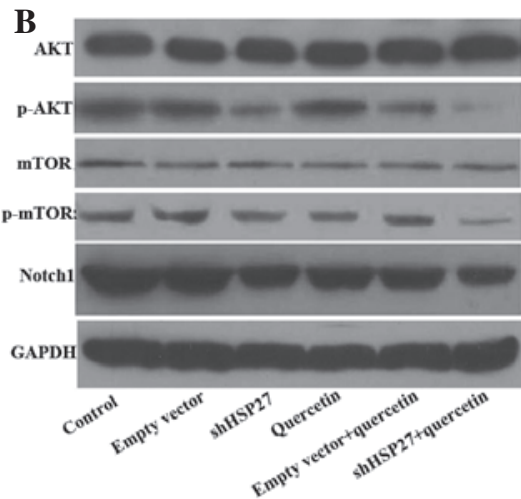

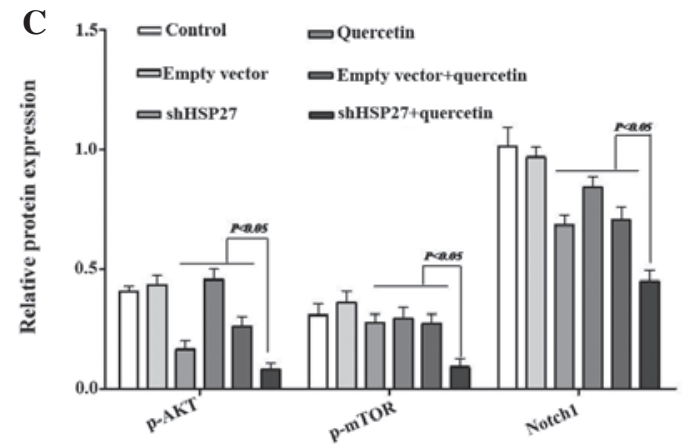

Figure 2. Effect of shHSP27 and quercetin on cell proliferation of U937 cells. (A) Cell viability was determined using a Cell Counting Kit-8 assay. (B) The expression of cell proliferation-associated proteins was assessed using western blot analysis. (C) Values are expressed as the mean \pm standard deviation of three experiments. shHSP27, small hairpin RNA specific for heat shock protein 27; p-mTOR, phosphorylated mammalian target of rapamycin.

A

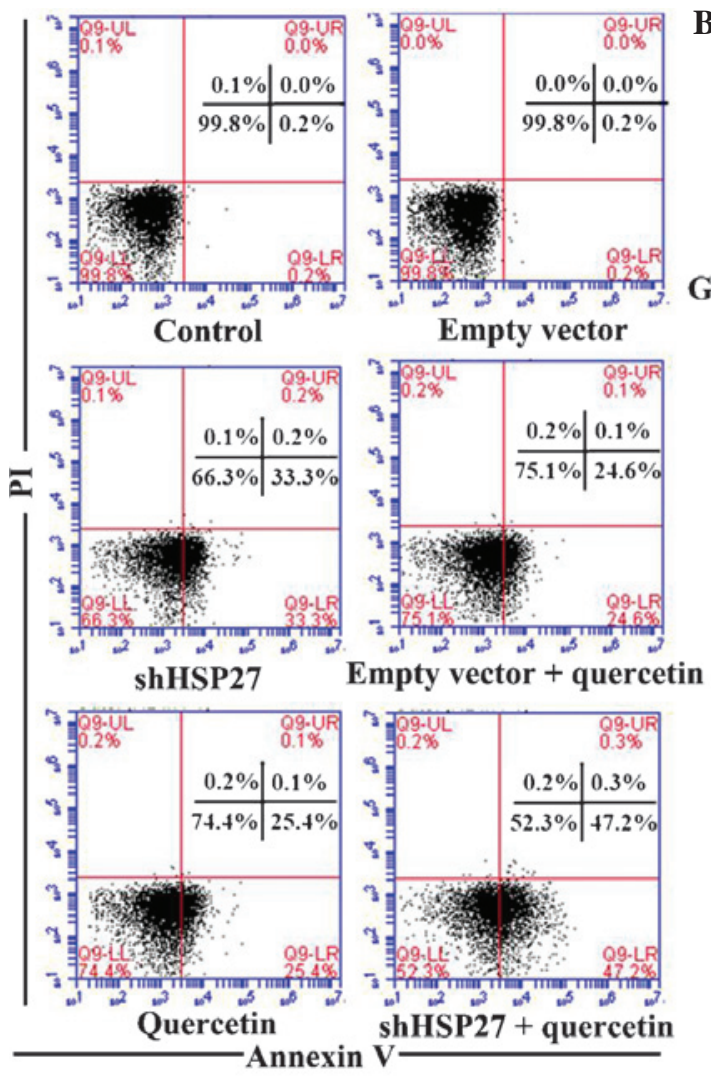

B

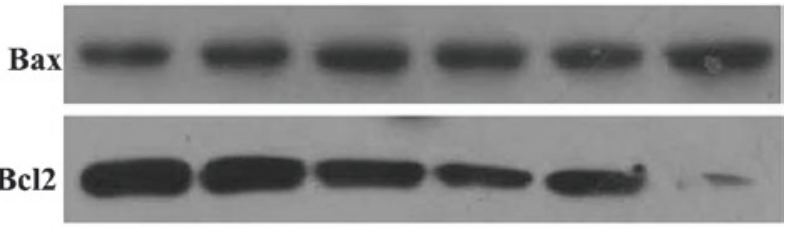

GAPDH
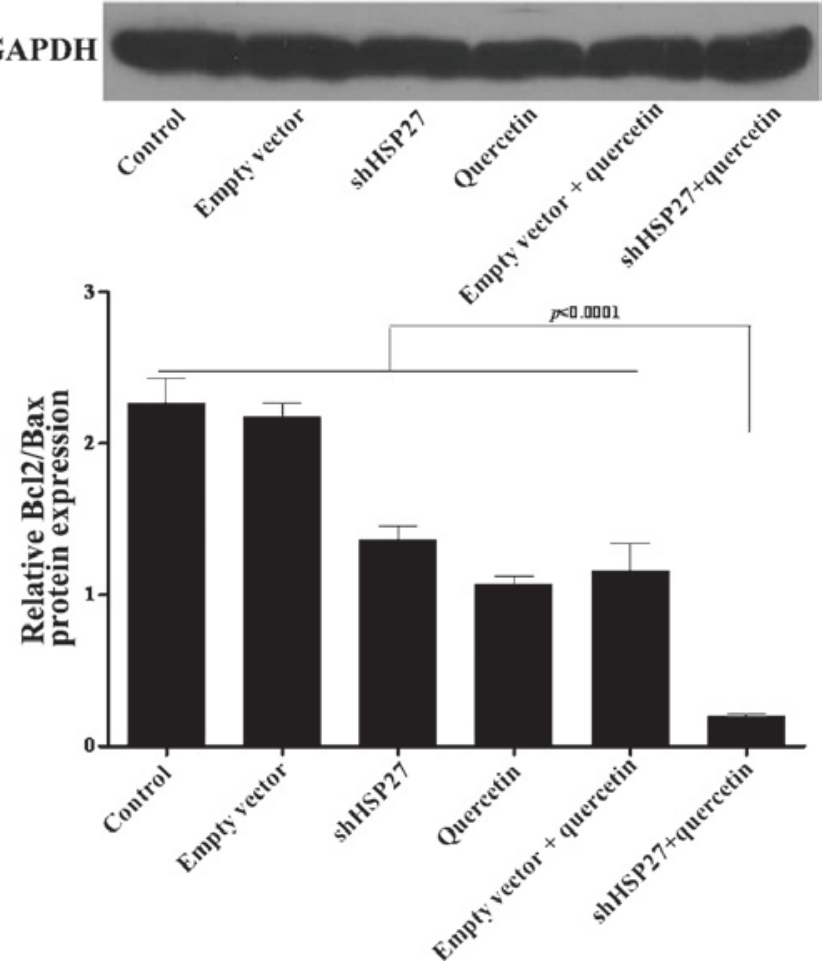

Figure 3. Effect of shHSP27 and quercetin on apoptotic rates were analyzed in U937 cells. (A) The apoptotic rate of U937 cells was analyzed by Annexin V/PI double staining and flow cytometric analysis. Cell populations in the quadrants were defined as follows: LL, viable cells; LR, early apoptotic cells; UR, late apoptotic cells; UL, necrotic cells. (B) Expression of Bcl2 and Bax in the experimental groups was assessed using western blot analysis. A representative blot is shown and the Bcl2/Bax ratio relative to GAPDH was determined by densitometric analysis. Values are expressed as the mean \pm standard deviation. $\mathrm{P}<0.001$ vs. the control group. PI, propidium iodide; shHSP27, small hairpin RNA specific for heat shock protein 27; Bcl2, B-cell lymphoma 2; Bax, Bcl2-associated $\mathrm{X}$ protein; UL, upper left; LR, lower right.

cancer models (35). To investigate the potential role of mTOR in the mechanism of action of quercetin and shHSP27, the expression of mTOR signaling proteins in U937 cells was assessed following treatment with quercetin and/or shHSP27. Western blot analysis showed that following treatment with quercetin, shHSP27 or their combination, the protein levels of p-AKT and p-mTOR were markedly decreased, while levels of total AKT were not obviously affected and those of total mTOR were only marginally reduced; furthermore, the protein expression of Notch1 was significantly decreased compared with that in the control or empty vector-treated groups (Fig. 2B and C). 
A

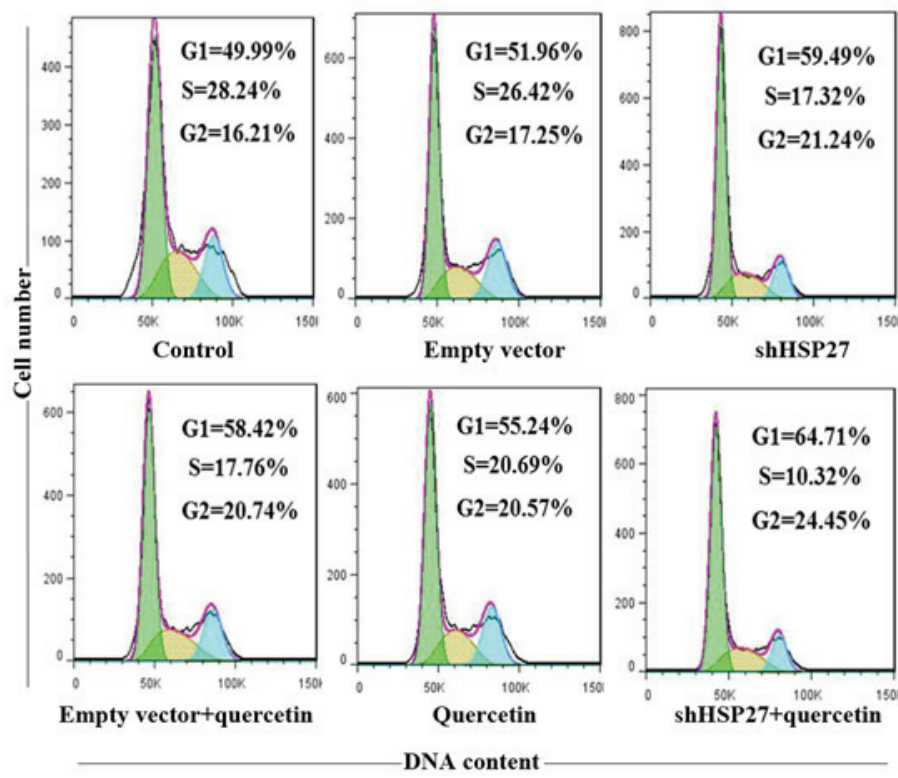

B
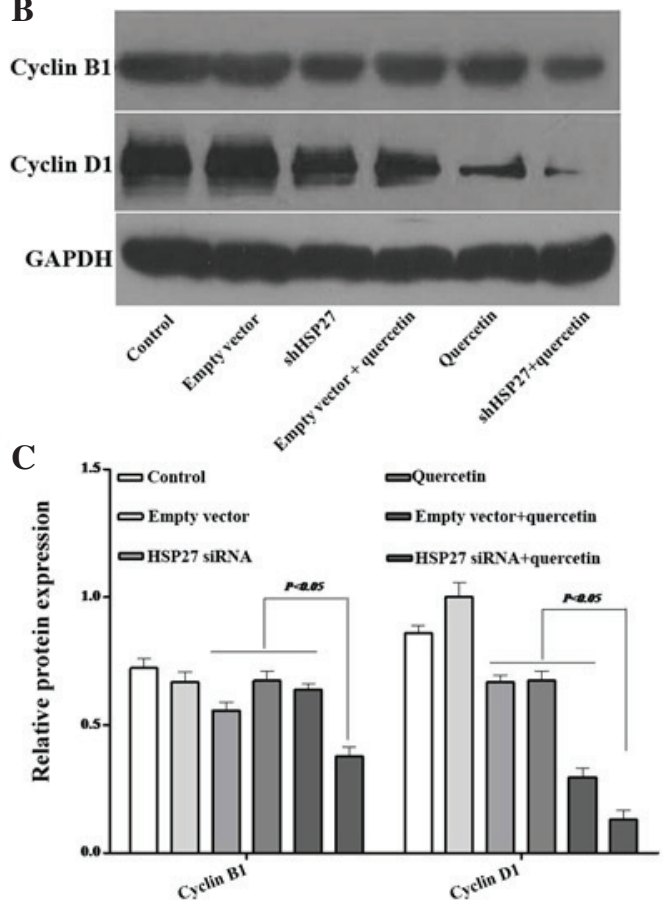

Figure 4. Effects of shHSP27 and quercetin on the cell cycle distribution. U937 cells were treated with quercetin for 24 h. (A) Propidium iodide staining and flow cytometric analysis were performed to determine the percentages of cells in G1, S and G2 phases. Representative images are shown. (B and C) The expression of the cell cycle-associated proteins cyclin B1 and cyclin D1 was assessed by western blot analysis. shHSP27, small hairpin RNA specific for heat shock protein 27.

HSP27 knockdown enhances quercetin-induced apoptosis of U937 cells. Following incubation of U937 cells with quercetin or shHSP27 plus quercetin for $48 \mathrm{~h}$, the percentage of apoptotic cells significantly increased from 25.4 to $47.2 \%$ (Fig. 3A). To investigate the underlying mechanism of this phenomenon, the protein expression of Bcl-2 and Bax, two genes that regulate cell apoptosis, was assessed. Bcl-2 is known inhibit apoptosis and to increase resistance to various apoptosis-stimulating factors, while not being associated with cell division and proliferation (36). Bax, a homologous gene of the Bcl-2 family, antagonizes the anti-apoptotic effect of the Bcl-2 by forming a heterodimer with $\mathrm{Bcl}-2$. It has been reported that the $\mathrm{Bcl}-2 / \mathrm{Bax}$ ratio is negatively correlated with the apoptotic rate (37). While treatment with quercetin or shHSP7 alone significantly reduced the $\mathrm{Bcl}-2 / \mathrm{Bax}$ ratio, their combination synergistically decreased the $\mathrm{Bcl}-2 / \mathrm{Bax}$ ratio by $\sim 90 \%$ and almost totally blocked Bcl-2 expression in U937 cells (Fig. 3B).

Quecetin plus shHSP27 induces U937-cell accumulation in G1 phase. Cell proliferation is controlled by the progression of the cell cycle (38). After treatment with quercetin alone or shHSP27 with quercetin for $48 \mathrm{~h}$, the fraction of cells in G1 phase significantly increased from 49.99 to 55.24 and $64.71 \%$, and the fraction of cells in $\mathrm{G} 2$ phase significantly increased from 16.21 to 20.57 and $24.45 \%$, however the fraction of cells in S phase decreased from 28.24 to 20.69 and $10.32 \%$, respectively (Fig. 4A). This result indicated that shHSP27 further enhanced the G1-phase arrest mediated by quercetin. Cyclins have an essential role in the regulation of the cell cycle (38). Cyclin B1 was the first cell cycle-associated protein to be identified (39); overexpression of cyclin B1 promotes cell cycle progression to $\mathrm{G} 2 / \mathrm{M}$-phase and may lead to uncontrolled cell proliferation and malignant transformation (40,41). It has been reported that inhibition of cyclin B1 expression decreases the G2/M-phase population, thereby suppressing cell growth and inducing apoptosis (42). Cyclin D1 is closely associated with the proliferation of cancer cells (43). By contrast to cyclin B1, cyclin D1 has an important role in the G1/S-phase transition, which may, however, promote the occurrence of tumors; it is therefore considered to be an oncoprotein (44). Quercetin significantly downregulated the protein expression of cyclin D1; furthermore, when combined with shHSP27, cyclinD1 expression was almost totally diminished. In addition, quercetin and shHSP27 reduced the expression of cyclin B1 (Fig. 4B and C). These results may explain for the reduced cell-cycle progression observed by flow cytometry.

Suppression of HSP27 enhances quercetin-induced inhibition of U937-cell adhesion. Adhesion of acute myeloid leukemia cells is linked with resistance to chemotherapy $(45,46)$, and adhesion of U937 cells to fibronectin via $\beta 1$ integrins has been shown to inhibit etoposide- and mitoxantrone-induced apoptosis (47).

Following treatment with quercetin, the adhesive capacity of U937 cells dropped by $\sim 30 \%$, while simultaneous transfection with shHSP27 vector further reduced cell adhesion to $\sim 80 \%$ (Fig. 5A and B). This result indicated that quercetin may serve as an adjuvant for chemotherapeutics.

Besides cellular adhesion, angiogenesis is required for invasive tumor-cell metastasis and represents an important target in the control of cancer progression (48). The HIF1 $\alpha /$ VEGF signaling pathway, which regulates angiogenesis (49), is activated by upstream mTOR signaling. As shown in Fig. 5C, shHSP27 and quercetin markedly decreased the protein expression of HIF1 $\alpha$ and VEGF in U937 cells. 
A

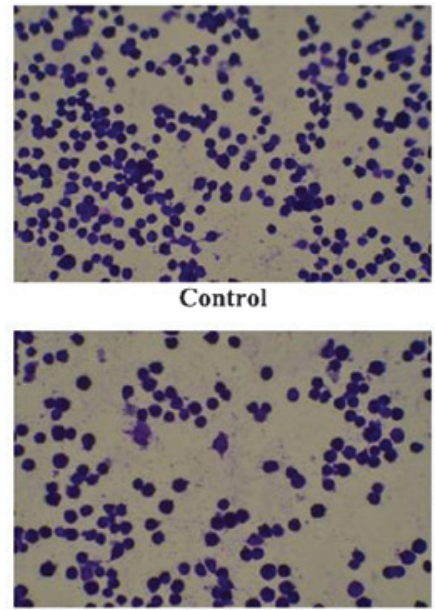

shHSP27

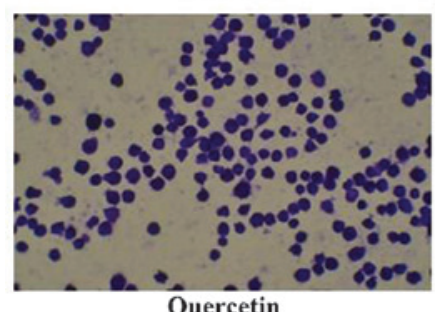

Quercetin

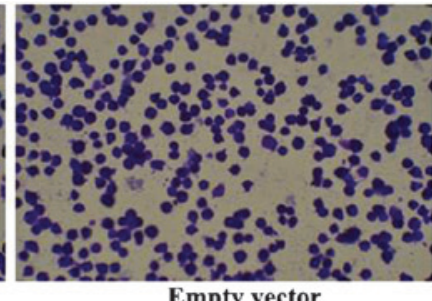

Empty vector

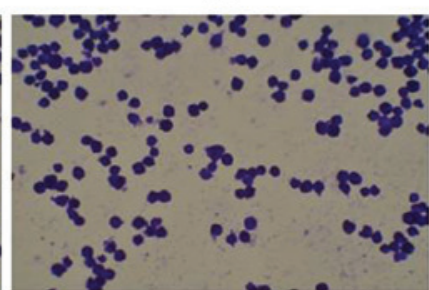

Empty vector + quercetin

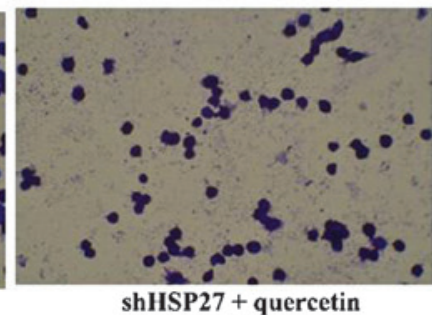

B
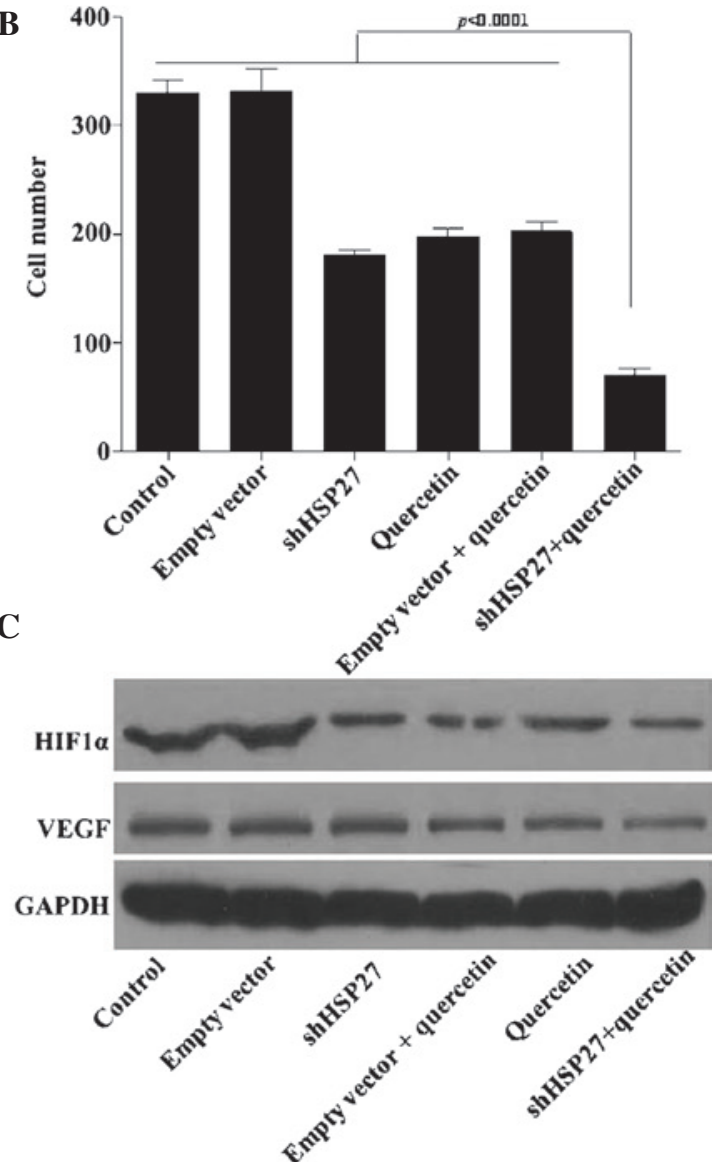

Figure 5. Effect of shHSP27 and quercetin on the adhesive properties of U937 cells. (A) Representative images of U937 cells subjected to the adhesion assay (magnification, x200). (B) The number of adhesive cells in A was quantified. Values are expressed as the mean \pm standard deviation of three experiments. (C) The expression of adhesion-associated proteins was determined using western blot analysis. Blots and cell images are representative of three separate experiments. shHSP27, small hairpin RNA specific for heat shock protein 27; VEGF, vascular endothelial growth factor; HIF, hypoxia-inducible factor.

Previous studies have indicated that HIF1 $\alpha$ increases the expression of anti-apoptotic Bcl-2 and reduces the expression of Bax (50); furthermore, in ovarian cancer cells, phosphoinositide-3 kinase (PI3K) was reported to mediate G1-to-S-phase progression and cyclin D1 expression through activation of AKT/mTOR/p70S6K1 signaling (51). In line with this, the results of the present study suggested that quercetin suppresses leukemia progression by inhibiting mTOR signaling and that this suppressive function can be further enhanced by shHSP27.

\section{Discussion}

Quercetin a major flavonoid contained in foods including apples, onions, tea, red wine. Several in vitro studies have shown that quercetin has activity against certain types of cancer cell $(27,52,53)$. Furthermore, a clinical study on patients with an inherited tendency to develop colorectal cancer found that combined dietary intake of quercetin and curcumin decreased the number and size of pre-cancerous rectal tumors (54). Leukemia is a common condition worldwide and affects all age groups; it is also the most common cancer type in children (55) and adolescents. In recent years, the incidence of leukemia has significantly increased (56).

Studies have found that quercetin inhibits the proliferation and induces apoptosis in human leukemia cells $(9,34)$; however, to the best of our knowledge, the anti-tumor effects of quercetin combined with shHSP27, as well as the underlying molecular mechanisms, have not been reported. The present study evaluated the anti-tumor effects of quercetin on the U937 acute myeloid leukemia cell line with HSP27 knockdown.

The results showed that the time-dependent inhibition of the proliferation of U937 cells by quercetin was enhanced with simultaneous transfection of shHSP27. Furthermore, cell cycle analysis showed that quercetin plus shHSP27 significantly induced the accumulation of U937 cells in G1 phase with a minor increase in $\mathrm{G} 2$ phase, which indicated that quercetin plus shHSP27 may inhibit the proliferation of U937 cells by blocking the cell cycle. In addition, the expression of cell cycle-associated proteins cyclin D1 and cyclin B1 in U937 cells treated with quercetin plus shHSP27 was decreased following treatment with quercetin plus shHSP27. Cyclin D1 is mainly involved in G1/S-phase transition (44), while cyclin B1 is associated with progression to $\mathrm{G} 2 / \mathrm{M}$ phase. These results indicated that shHSP27 plus quercetin blocked cell cycle progression by inhibiting the expression of the cell-cycle proteins cyclin D1 and -B1.

Evasion of apoptosis is a key factor during carcinogenesis, cancer progression and drug resistance, while induction of apoptosis is a desirable property of anti-cancer treatments (57). The present study found that the percentage 
of apoptotic U937 cells significantly increased after treatment with quercetin plus shHSP27. Furthermore, the expression of apoptotic signaling proteins was detected, which revealed that the expression of anti-apoptotic protein Bcl-2 decreased, while that of pro-apoptotic protein Bax in U937 cells increased when treated with shHSP27 and quercetin. This result indicated that shHSP27 plus quercetin induced cell apoptosis by reducing the Bcl-2/Bax ratio in U937 cells.

Cell adhesion has a vital role in tumor metastasis and the adhesion assay performed in the present study revealed a significant inhibitory effect of shHSP27 plus quercetin compared with that of quercetin only. In addition, angiogenesis is associated with the occurrence and prognosis of leukemia $(58,59)$. VEGF, the primary factor stimulating blood-vessel growth, has been confirmed to be elevated in leukemia and is vital for its pathogenesis and progression (60). The present study revealed that quercetin plus shHSP27 inhibited VEGF expression in U937 cells.

The Akt and mTOR (PI3K/Akt/mTOR) signaling network is important in leukemia, where it regulates cell growth and survival (61). Proteins demonstrated to be involved in regulating apoptosis, cell cycle and angiogenesis of U937 cells in the present study have all been confirmed as parts of the mTOR signaling network in other diseases $(28,30,35,51,61,62)$, while they have not been previously determined in leukemia. Levels of p-AKT and p-mTOR were decreased following treatment with shHSP27 plus quercetin; furthermore, Notch1, Bcl-2, cyclin D1, HIF1 $\alpha$ and VEGF were decreased. These proteins constitute a huge network regulated by mTOR expression, and mTOR signaling has a critical role in the regulation of tumor-cell motility, invasion and cancer metastasis (63). In order to further determine the therapeutic potential of quercetin plus shHSP27 in leukemia, the effects of quercetin on the mTOR-regulated signaling network require further elucidation.

In conclusion, the present study demonstrated that, compared with quercetin or shHSP 27 alone, combined treatment with quercetin plus shHSP27 significantly inhibited the proliferation and adhesion as well as induced apoptosis and cell-cycle arrest in U937 human leukemia cells. These anti-tumor effects may mainly depend on the inhibition of the mTOR signal network. Quercetin plus shHSP27 synergistically decreased the cellular adhesion capacity of leukemia cells and HSP27 knockdown may therefore potentiate the efficiency of chemotherapies of human leukemia.

\section{Acknowledgements}

This study was supported by the Scientific Research Project of Heilongjiang Province Department of Education (no. 12541530).

\section{References}

1. Kuttan G, Pratheeshkumar P, Manu KA and Kuttan R: Inhibition of tumor progression by naturally occurring terpenoids. Pharm Biol 49: 995-1007, 2011.

2. Pratheeshkumar P, Sreekala C, Zhang Z, Budhraja A, Ding S, Son YO, Wang X, Hitron A, Hyun-Jung K, Wang L, et al: Cancer prevention with promising natural products: Mechanisms of action and molecular targets. Anticancer Agents Med Chem 12: $1159-1184,2012$
3. Larson AJ, Symons JD and Jalili T: Therapeutic potential of quercetin to decrease blood pressure: Review of efficacy and mechanisms. Adv Nutr 3: 39-46, 2012.

4. Okamoto T: Safety of quercetin for clinical application (Review). Int J Mol Med 16: 275-278, 2005.

5. Formica JV and Regelson W: Review of the biology of Quercetin and related bioflavonoids. Food Chem Toxicol 33: 1061-1080, 1995.

6. Lee JC, Kim J, Park JK, Chung GH and Jang YS: The antioxidant, rather than prooxidant, activities of quercetin on normal cells: Quercetin protects mouse thymocytes from glucose oxidase-mediated apoptosis. Exp Cell Res 291: 386-397, 2003.

7. Liesveld JL, Abboud CN, Lu C, McNair C, Menon A, Smith A, Rosell K and Rapoport AP: Flavonoid effects on normal and leukemic cells. Leuk Res 27: 517-527, 2003.

8. Cheng S, Gao N, Zhang Z, Chen G, Budhraja A, Ke Z, Son YO, Wang X, Luo J and Shi X: Quercetin induces tumor-selective apoptosis through downregulation of Mcl-1 and activation of Bax. Clin Cancer Res 16: 5679-5691, 2010.

9. Kang TB and Liang NC: Studies on the inhibitory effects of quercetin on the growth of HL-60 leukemia cells. Biochem Pharmacol 54: 1013-1018, 1997.

10. Román-Gómez J, Cordeu L, Agirre X, Jiménez-Velasco A, San José-Eneriz E, Garate L, Calasanz MJ, Heiniger A, Torres A and Prosper F: Epigenetic regulation of Wnt-signaling pathway in acute lymphoblastic leukemia. Blood 109: 3462-3469, 2007.

11. Kimura A: Radiation associated leukemia and myelodysplastic syndrome. Nihon Rinsho 70: 431-435, 2012 (In Chinese).

12. Noshchenko AG, Bondar OY and Drozdova VD: Radiationinduced leukemia among children aged 0-5 years at the time of the Chernobyl accident. Int J Cancer 127: 412-426, 2010.

13. Malagoli C, Malavolti M, Costanzini S, Fabbri S, Tezzi S, Palazzi G, Arcolin E and Vinceti M: Increased incidence of childhood leukemia in urban areas: a population-based casecontrol study. Epidemiol Prev 39: 102-107, 2015.

14. Garcia-Perez J, López-Abente G, Gómez-Barroso D, Morales-Piga A, Romaguera EP, Tamayo I, Fernández-Navarro P and Ramis R: Childhood leukemia and residential proximity to industrial and urban sites. Environ Res 140: 542-553, 2015.

15. Zeeshan R, Sultan S, Irfan SM, Kakar J and Hameed MA: Clinico-hematological profile of patients with B-chronic lymphoid leukemia in Pakistan. Asian Pac J Cancer Prev 16: 793-796, 2015.

16. Khalafalla MM, Abdellatef E, Daffalla HM, et al: Antileukemia activity from root cultures of Vernonia amygdalina. J Med Plants Res 3: 556-562, 2009.

17. Bukau B and Horwich AL: The Hsp70 and Hsp60 chaperone machines. Cell 92: 351-366, 1998.

18. Polla BS, Kantengwa S, Gleich GJ, Kondo M, Reimert CM and Junod AF: Spontaneous heat shock protein synthesis by alveolar macrophages in interstitial lung disease associated with phagocytosis of eosinophils. Eur Respir J 6: 483-488, 1993.

19. Taba K, Kuramitsu Y, Ryozawa S, Yoshida K, Tanaka T, Maehara S, Maehara Y, Sakaida I and Nakamura K: Heat-shock protein 27 is phosphorylated in gemcitabine-resistant pancreatic cancer cells. Anticancer Res 30: 2539-2543, 2010.

20. Carper SW, Duffy JJ and Gerner EW: Heat shock proteins in thermotolerance and other cellular processes. Cancer Res 47: 5249-5255, 1987.

21. Ricci JE, Maulon L, Battaglione-Hofman V, Bertolotto C, Luciano F, Mari B, Hofman P and Auberger P: A Jurkat T cell variant resistant to death receptor-induced apoptosis. Correlation with heat shock protein (Hsp) 27 and 70 levels. Eur Cytokine Netw 12: 126-134, 2001.

22. Pandey P, Farber R, Nakazawa A, Kumar S, Bharti A, Nalin C, Weichselbaum R, Kufe D and Kharbanda S: Hsp27 functions as a negative regulator of cytochrome c-dependent activation of procaspase-3. Oncogene 19: 1975-1981, 2000.

23. Garrido C, Ottavi P, Fromentin A, Hammann A, Arrigo AP, Chauffert B and Mehlen P: HSP27 as a mediator of confluence-dependent resistance to cell death induced by anticancer drugs. Cancer Res 57: 2661-2667, 1997.

24. Garrido C, Bruey JM, Fromentin A, Hammann A, Arrigo AP and Solary E: HSP27 inhibits cytochrome c-dependent activation of procaspase-9. FASEB J 13: 2061-2070, 1999.

25. Piantelli M, Tatone D, Castrilli G, Savini F, Maggiano N, Larocca LM, Ranelletti FO and Natali PG: Quercetin and tamoxifen sensitize human melanoma cells to hyperthermia. Melanoma Res 11: 469-476, 2001. 
26. Jakubowicz-Gil J, Rzymowska J and Gawron A: Quercetin, apoptosis, heat shock. Biochem Pharmacol 64: 1591-1595, 2002.

27. Chen SF, Nieh S, Jao SW, Liu CL, Wu CH, Chang YC, Yang CY and Lin YS: Quercetin suppresses drug-resistant spheres via the p38 MAPK-Hsp27 apoptotic pathway in oral cancer cells. PLoS One 7: e49275, 2012.

28. Zhou H and Huang S: Role of mTOR signaling in tumor cell motility, invasion and metastasis. Curr Protein Pept Sci 12: 30-42, 2011.

29. Efeyan A and Sabatini DM: mTOR and cancer: Many loops in one pathway. Curr Opin Cell Biol 22: 169-176, 2010.

30. Pratheeshkumar P, Budhraja A, Son YO, Wang X, Zhang Z, Ding S, Wang L, Hitron A, Lee JC, Xu M, et al: Quercetin inhibits angiogenesis mediated human prostate tumor growth by targeting VEGFR- 2 regulated AKT/mTOR/P70S6K signaling pathways. PLoS One 7: e47516, 2012

31. Bruning A: Inhibition of mTOR signaling by quercetin in cancer treatment and prevention. Anticancer Agents Med Chem 13: $1025-1031,2013$.

32. O'Callaghan-Sunol C, Gabai VL and Sherman MY: Hsp27 modulates p53 signaling and suppresses cellular senescence. Cancer Res 67: 11779-11788, 2007

33. Niu G, Yin S, Xie S, Li Y, Nie D, Ma L, Wang X and Wu Y: Quercetin induces apoptosis by activating caspase-3 and regulating Bcl-2 and cyclooxygenase-2 pathways in human HL-60 cells. Acta Biochim Biophys Sin (Shanghai) 43: 30-37, 2011.

34. Mahbub AA, Le Maitre CL, Haywood-Small SL, McDougall GJ, Cross NA and Jordan-Mahy N: Differential effects of polyphenols on proliferation and apoptosis in human myeloid and lymphoid leukemia cell lines. Anticancer Agents Med Chem 13: 1601-1613, 2013.

35. Hansel DE, Platt E, Orloff M, Harwalker J, Sethu S, Hicks JL, De Marzo A, Steinle RE, Hsi ED, Theodorescu D, et al: Mammalian target of rapamycin (mTOR) regulates cellular proliferation and tumor growth in urothelial carcinoma. Am J Pathol 176: 3062-3072, 2010.

36. Osorio LM, Jondal M and Aguilar-Santelises M: Regulation of B-CLL apoptosis through membrane receptors and Bcl-2 family proteins. Leuk Lymphoma 30: 247-256, 1998.

37. Podhorecka M, Halicka D, Klimek P, Kowal M, Chocholska S and Dmoszynska A: Simvastatin and purine analogs have a synergic effect on apoptosis of chronic lymphocytic leukemia cells. Ann Hematol 89: 1115-1124, 2010.

38. Malumbres M and Barbacid M: Cell cycle, CDKs and cancer: A changing paradigm. Nat Rev Cancer 9: 153-166, 2009.

39. Evans T, Rosenthal ET, Youngblom J, Distel D and Hunt T: Cyclin: A protein specified by maternal mRNA in sea urchin eggs that is destroyed at each cleavage division. Cell 33: 389-396, 1983.

40. Hwang A, Maity A, McKenna WG and Muschel RJ: Cell cycle-dependent regulation of the cyclin B1 promoter. J Biol Chem 270: 28419-28424, 1995.

41. Hartwell LH and Kastan MB: Cell cycle control and cancer. Science 266: 1821-1828, 1994.

42. Yuan J, Kramer A, Matthess Y, Yan R, Spänkuch B, Gätje R, Knecht R, Kaufmann M and Strebhardt K: Stable gene silencing of cyclin B1 in tumor cells increases susceptibility to taxol and leads to growth arrest in vivo. Oncogene 25: 1753-1762, 2006.

43. Nakata Y, Shetzline S, Sakashita C, Kalota A, Rallapalli R, Rudnick SI, Zhang Y, Emerson SG and Gewirtz AM: c-Myb contributes to G2/M cell cycle transition in human hematopoietic cells by direct regulation of cyclin B1 expression. Mol Cell Biol 27: 2048-2058, 2007.

44. Donnellan R and Chetty R: Cyclin D1 and human neoplasia. Mol Pathol 51: 1-7, 1998.

45. Becker PS: Dependence of acute myeloid leukemia on adhesion within the bone marrow microenvironment. Scientific World Journal 2012: 856467, 2012.

46. Koukoulis GK, Patriarca C and Gould VE: Adhesion molecules and tumor metastasis. Hum Pathol 29: 889-892, 1998.
47. Hazlehurst LA, Valkov N, Wisner L, Storey JA, Boulware D, Sullivan DM and Dalton WS: Reduction in drug-induced DNA double-strand breaks associated with beta1 integrin-mediated adhesion correlates with drug resistance in U937 cells. Blood 98: 1897-1903, 2001.

48. Folkman J: Role of angiogenesis in tumor growth and metastasis. Semin Oncol 29 (Suppl 6): S15-S18, 2002.

49. Dai $Y, X u$ M, Wang Y, Pasha Z, Li T and Ashraf M: HIF-1alpha induced-VEGF overexpression in bone marrow stem cells protects cardiomyocytes against ischemia. J Mol Cell Cardiol 42: 1036-1044, 2007

50. Sasabe E, Tatemoto Y, Li D, Yamamoto T and Osaki T: Mechanism of HIF-1alpha-dependent suppression of hypoxia-induced apoptosis in squamous cell carcinoma cells. Cancer Sci 96: 394-402, 2005.

51. Gao N, Flynn DC, Zhang Z, Zhong XS, Walker V, Liu KJ, Shi X and Jiang BH: G1 cell cycle progression and the expression of $\mathrm{G} 1$ cyclins are regulated by $\mathrm{PI} 3 \mathrm{~K} / \mathrm{AKT} / \mathrm{mTOR} / \mathrm{p} 70 \mathrm{~S} 6 \mathrm{~K} 1$ signaling in human ovarian cancer cells. Am J Physiol Cell Physiol 287: C281-C291, 2004.

52. Rong Y, Yang EB, Zhang K and Mack P: Quercetin-induced apoptosis in the monoblastoid cell line U937 in vitro and the regulation of heat shock proteins expression. Anticancer Res 20 (6B): 4339-4345, 2000 .

53. Scambia G, Ranelletti FO, Panici PB, De Vincenzo R, Bonanno G, Ferrandina G, Piantelli M, Bussa S, Rumi C and Cianfriglia M: Quercetin potentiates the effect of adriamycin in a multidrug-resistant MCF-7 human breast-cancer cell line: P-glycoprotein as a possible target. Cancer Chemother Pharmacol 34: 459-464, 1994.

54. Volate SR, Davenport DM, Muga SJ and Wargovich MJ: Modulation of aberrant crypt foci and apoptosis by dietary herbal supplements (quercetin, curcumin, silymarin, ginseng and rutin). Carcinogenesis 26: 1450-1456, 2005.

55. Zwaan CM, Kolb EA, Reinhardt D, Abrahamsson J, Adachi S, Aplenc R, De Bont ES, De Moerloose B, Dworzak M, Gibson BE, et al: Collaborative Efforts Driving Progress in Pediatric Acute Myeloid Leukemia. J Clin Oncol 33: 29492962, 2015

56. Katz AJ, Chia VM, Schoonen WM and Kelsh MA: Acute lymphoblastic leukemia: an assessment of international incidence, survival, and disease burden. Cancer Causes Control 26: 1627-1642, 2015.

57. Gregoire, M, Ligeza-Poisson C, Juge-Morineau N, Spisek R: Anti-cancer therapy using dendritic cells and apoptotic tumour cells: pre-clinical data in human mesothelioma and acute myeloid leukaemia. Vaccine 21: 791-794, 2003.

58. Schmidt T and Carmeliet P: Angiogenesis: A target in solid tumors, also in leukemia? Hematology Am Soc Hematol Educ Program 2011: 1-8, 2011.

59. Trujillo A, McGee C and Cogle CR: Angiogenesis in acute myeloid leukemia and opportunities for novel therapies. J Oncol 2012: 128608, 2012.

60. Kampen KR, Ter Elst A and de Bont ES: Vascular endothelial growth factor signaling in acute myeloid leukemia. Cell Mol Life Sci 70: 1307-1317, 2013.

61. Neri LM, Cani A, Martelli AM, Simioni C, Junghanss C, Tabellini G, Ricci F, Tazzari PL, Pagliaro P, McCubrey JA and Capitani S: Targeting the PI3K/Akt/mTOR signaling pathway in B-precursor acute lymphoblastic leukemia and its therapeutic potential. Leukemia 28: 739-748, 2014.

62. Wang K, Liu R, Li J, Mao J, Lei Y, Wu J, Zeng J, Zhang T, $\mathrm{Wu} \mathrm{H}$, Chen L, et al: Quercetin induces protective autophagy in gastric cancer cells: Involvement of Akt-mTOR- and hypoxia-induced factor $1 \alpha$-mediated signaling. Autophagy 7 : 966-978, 2011

63. Alayev A and Holz MK: mTOR signaling for biological control and cancer. J Cell Physiol 228: 1658-1664, 2013. 